\title{
PROBLEMAS DE INVESTIGACION SOBRE LA UNIVERSIDAD COLONIAL ${ }^{* 74}$
}

Renán Silva**

1.

\begin{abstract}
"En 1659, Fray Tomás Solano y Robles, agustino originario de Nueva Granada, se presenta ante la inquisición madrileña. Viene, como fiel católico, a descargar su conciencia y demostrar su espíritu de colaboración con las fuerzas encargadas de velar por la salud del cuerpo social, salud que, como es sabido, requiere de cuando en cuando la amputación de los miembros enfermos. En suma, viene a delatar a alguien. Lo exige la salvación de su alma, y acaso también la de su cuerpo; el tribunal podría llegar a enterarse de que no ha procedido con la debida diligencia. Cuenta que, viniendo a Europa desde Colombia (sic), su barco ha sido apresado por los ingleses; liberado en Londres, ha pasado a Ámsterdam; un cómico sevillano —no judío-, llamado Lorenzo Escudero, se ha convertido al judaísmo, pese a las presiones en contra de sus compatriotas más fieles; Fray Tomás informa de ello, por si a Escudero se le ocurriera volver a España. El inquisidor aprovecha la ocasión para preguntarle por otros españoles que pudieran judaizar en Ámsterdam. En su relato, Solano dice que conoció al doctor Prado, que había estudiado en Alcalá, a un fulano De Espinosa, quE entiende era natural de una de las ciudades de Holanda porque había estudiado en Leidem y era buen filósofo". Sabe que los han expulsado de la comunidad judía por ateos, por decir "que el alma moría con el cuerpo ni había Dios sino filosofalmente" ${ }^{\prime 7}$.
\end{abstract}

Este pequeño hecho tan anodino y común en su tiempo pero que no dejaré de situar como importante episodio cultural, sucedido tan lejos de nosotros y al que tal vez en superficie no nos une sino el azar de uno o dos nombres en común, me ha parecido desde tiempo atrás de una fuerza que sorprende como ilustración de los avatares del pensamiento colonial en la sociedad Neogranadina, pues define con nitidez el rasgo central de aquella cultura: el dogmatismo.

Escribo una "Cultura Dogmática" y esto merece alguna aclaración: en contra de nuestros mejores deseos, toda cultura es, - profunda o superficialmente-, dogmática. Toda Formación Cultural contiene "in nuce" elementos de freno y sojuzgamiento, de barrera y prohibición, de límites y de impensados. El pensamiento contemporáneo, aun en

\footnotetext{
* El presente trabajo forma parte de la investigación "Historia de la Práctica Pedagógica durante la Colonia", del Centro de Investigaciones de la Universidad Pedagógica Nacional. Tal proyecto forma parte de la investigación "Hacia una historia de la práctica pedagógica en Colombia" en que participan la Universidad de Antioquia, la Universidad del Valle, la Universidad Nacional de Colombia y la Universidad Pedagógica Nacional, con ayuda financiera de Colciencias.

${ }^{74}$ Desde luego que se entenderá en el sentido más fuerte el título colocado al presente trabajo. Se trata de una investigación en proceso de cuyos resultados nos encontramos aún demasiado lejos. Por lo demás, frente a las equivocaciones y lagunas presentes repetiremos la fórmula ritual con que el saber retórico gustaba siempre responder en estas situaciones: excusatio propter infirmitatem...

${ }^{* *}$ Sociólogo Universidad de la Salle. Investigador CIUP.

75 "La noticia se la debemos a la inquisición, bien informada hasta extremos aún hoy difícilmente superables, pese a los brillantes logros que de entonces acá se han obtenido en la fiscalización de vidas y conciencias". Peña, Vidal. Prólogo, traducción y notas a: Ética. De Espinoza Baruch. Madrid, Editora Nacional, 1979. p. 16 y ss.
} 
sus mejores expresiones, que se figura tan libre y nómade, lo sabe muy bien, así lo haya tenido que aprender a través de duros desengaños ${ }^{76}$.

Pero aquí sitúo como rasgo central, en la sociedad colonial, el elemento dogmático, en un sentido aún más fuerte y preciso. No se trata del peligro de cerco al pensamiento que, en germen por lo menos, guarda doctrina y toda cultura, así sea sólo por su tendencia a la auto-conservación. Se trata, con exactitud, de una cultura que reproduce y dispersa por todo el espacio posible una irreprimible tendencia a desconfiar del pensamiento (antes que por haber obrado se peca con sólo haberlo pensado); que mantiene la verdad en clausura, atada a una única intertextualidad (el texto canónico), sin más desplazamiento posible que el "comentario"; y que produce una jerarquía especial (La inquisición policía de la Fe) que vigila y controla cada uno de los pensamientos mayores y menores de sus miembros para asegurar una profunda, paralizante y aterradora uniformidad discursiva. Mecanismos institucionales de control del discurso se ponen en marcha entonces para garantizar la exclusión de la duda, figura del pensamiento que se encuentra por entero proscrita.

Observemos, así sea brevemente, ese Teatro en que ejerció sus poderes y alimentó sus fuerzas esa cultura, y comprendemos entonces porqué las instituciones que transmitieron el saber en su forma más elaborada, las modalidades enunciativas que rigieron el "decir" y los tipos de saberes que circularon fueron un amplio y fértil territorio para la existencia de esa cultura dogmática.

\section{A. Corporaciones del Saber ${ }^{77}$}

Como se sabe, una misma palabra, en períodos históricos distintos, encubre objetos y realidades por completo diferentes. Cuando a esto se suma la persistente tendencia analógica del pensamiento, sólo se está a un paso de volver a confundir "al arzobispo de Canterbury con el pontífice Samuel". En precaución de todo ello y para evitar contrasentidos, el análisis debe fijar con claridad las líneas más sobresalientes que definen el objeto que se intenta considerar y poder establecer así su forma singular.

Aunque muy a menudo se soslaye, $o$ no se ponga de relieve con la suficiente intensidad, hay que recordar, para empezar a decir algo, que durante los siglos XVII y XVIII, bajo la palabra "Universidad" (Colegio y Academia) existió algo por completo diferente de cualquier imagen cercana que hoy podamos tener. Por ello es complicada y riesgosa la expresión, ya fijada y aceptada por el uso, de "Universidad Colonial". Se trataba más bien, en rigor, de especies de corporaciones semi-eclesiásticas estructuradas como grupos cerrados, de número limitado y bien definido, cuyos criterios de pertenencia, perfectamente reglamentados, permanecieron inalterados por casi dos centurias. Esos criterios de pertenencia remitían a la producción institucional de un "grupo de casta" en donde a los criterios económicos se sumaban criterios raciales y jurídicos y una modalidad de acceso casi patrimonial. Antes que como "Universitas", en el sentido medieval $^{78}$, se orientaban como corporaciones de orden religioso para la defensa y pro-

\footnotetext{
${ }^{76}$ Ironizando, con extrema agudeza, sobre los problemas del dogmatismo contemporáneo, Bertol Brecht escribía: "He observado dijo el señor K - que mucha gente se aleja, intimidada, de nuestra doctrina, por la sencilla razón de que tenemos respuesta para todo. ¿No sería conveniente que en interés de la propaganda elaborásemos una lista de los problemas para los que aún no hemos encontrado solución? Brecht, Bertol. Historia de Almanaque. Madrid, Alianza Editorial, 1975.

${ }^{77}$ La documentación básica sobre la situación educativa colonial puede leerse en: Hernández de Alba, Guillermo. Documentos para La historia de la educación en Colombia. (Hasta el presente publicados cuatro tomos). Bogotá, Patronato Colombiano de Artes y Ciencias.

${ }^{78}$ V. Gilson, Ettienne. La filosofía en la Edad Media. Madrid, editorial Gredas, 1965. p. 366 y as.
} 
pagación de la fe, organizadas según un régimen interno de control total sobre todo el ritmo diario de sus componentes, y con una perfecta jerarquización de los saberes, en cuyo pináculo el saber teológico y religioso ocupaba el lugar central.

Desde el punto de vista de su relación con el discurso eran corporaciones ordenadas en términos de conservar y perpetuar un mismo grupo de verdades que se distribuían según reglas estrictas y dentro de un espacio cerrado, funcionando a la manera de Sociedades de Discurso, bajo el obligado reconocimiento - a través del Juramento- de esas reglas y verdades. En ese tipo de instituciones se formaron por más de dos siglos los dos grupos profesionales que constituyeron el núcleo principal de la intelectualidad colonial: los clérigos y los abogados, pareciendo ser más importante de los dos - como intelectualidad- el primero, no sólo en términos cuantitativos, sino en relación con el papel que desempeñaron -la propagación de la fe-_- y del discurso que instrumentaron -el discurso religioso-, discurso de cuya importancia en la sociedad colonial nadie puede dudar.

Pero estas sociedades de discurso operaban también, en otra fase de su desempeño, como Grupos Doctrinales. Se trata del momento de la difusión de la doctrina. Y lo que era antes, principalmente, un discurso teológico, se desdoblaba y traducía en discurso religioso. La obligada conversión de las comunidades indígenas a la fe, la permanente vigilancia sobre las amenazas de herejía ("formulación de enunciados inasimilables"), la atención de los "casos de conciencia", la práctica de la confesión, la producción de sermones, todo ello revestía el carácter de función intelectual por excelencia, en una sociedad cuyo tejido estaba firmemente cimentado en las creencias religiosas.

Algún día habrá que leer con atención y ánimo desprevenido todos esos devocionarios, libros de horas y piadosos, libros de sermones y catecismos en los cuales quedó la huella de un discurso, moral y religioso por su forma, cuya circulación fue dominante y cuyos funcionarios se formaron en aquellas extrañas corporaciones del saber de las que sólo por comodidad podemos seguir hablando como de "universidades".

\section{B. Dominación del pensamiento Teológico}

Ningún fenómeno en la sociedad colonial escapa al filtro religioso.

La religión es el hecho cultural de masa por excelencia. En todo el curso de la vida, y esto para todos los grupos sociales, todas las prácticas cotidianas de los hombres desde el nacimiento hasta la muerte- están insertas en el universo de la religión. Ella es el alimento espiritual diario, el bálsamo de toda pena, y el complemento de cualquier alegría; la forma natural a través de la cual se inscribe cualquier acontecimiento, se inicia cualquier empresa, se experimenta cualquier novedad, se expresa cualquier inquietud, se piensa y se medita cualquier interrogación. Pero no hay que interpretar este fenómeno de una presencia pan-religiosa superficialmente, limitándolo a la categoría de un fenómeno de "superestructura" —en el sentido vanal-, o reduciéndolo, a la manera de los mecanicistas, a un "instrumento" manejable a voluntad" en manos de una "clase". La religión era el aroma espiritual natural en el que todo se planteaba. Los fenómenos de la piedad y la fe, "cuyo significado profundo hay que volver a plantear" (Mandrou), lo atravesaban todo, y eran de manera permanente reforzados por la prédica religiosa.

En condiciones como esas, es claro que el saber principal en el lugar de formación de los grupos intelectuales no podía ser otro que el teológico, constituido no sólo en la forma dominante del conocimiento sino en el ordenador y jerarquizador de toda otra clase de 
saberes. Al predominio del hecho y doctrina religiosos se correspondía bien la estructura jerárquica de los saberes, asegurando para la teología, —que aunque parezca paradójico es una forma del saber sobre el Hombre-, el lugar central en los estudios y ser el patrón de medida en torno del cual los demás saberes se ordenaban. Ya fuera bajo la forma de teología dogmática o de teología moral, los ni-ventanos de las bibliotecas y las listas de los manuscritos refrendan esta opinión, aunque sobre los aspectos precisos y detallados de los conocimientos teológicos que circularon sea bien poco lo que sabemos ${ }^{79}$.

Y sin embargo, no hay que plantearse tal evidencia de una manera racionalista y pesimista, tal como lo hacen algunos autores ${ }^{80}$. La teología, "esa forma de literatura fantástica" en que se piensa sobre el hombre y su destino, es una modalidad cultural singular que sufre en los azares de la historia las vicisitudes de cualquier saber. Como lo indica R. Barthes, de manera tan justa y apropiada, "Es menester.., repetir que las ciencias no son eternas. Son valores que suben y descienden en una bolsa, la bolsa de la Historia. Basta a este respecto recordar la suerte bursátil de la teología, discurso hoy exiguo y sin embargo en otras épocas ciencia soberana hasta el punto de colocársela por fuera y por encima del Septenium" ${ }^{11}$ - Hoy mismo asistimos a un remozamiento sorprendente del saber teológico en pensadores de tanta eficacia y disparidad como J.L. Borges, P. Ricoeur, o P. Klosowsky, pues la teología como saber también es campo factible y propicio a las más paradójicas disputas y a los más extraños usos. Para citar sólo un caso, traigo a cuento uno de los de más inaudita ironía, en mi opinión. En 1918, Herman Hesse rescató y tradujo los "Dialogus Miraculorum" de Caesarius (1122 aproximadamente), prior del convento de Heinterbach, libro de instrucción y devoción teológicas, escrito con la intención de enseñar a los novicios, y que Hesse reeditó en edición expresamente dirigida a los prisioneros de guerra alemanes ${ }^{82}$. La prudencia aconseja suspender el juicio entre tanto. Podría darse el caso de que los manuscritos teológico-filosóficos coloniales contuvieran más de un sorpresa.

\section{Una cultura del silogismo}

Durante todo el período colonial una modalidad enunciativa ocupa sin disputa el lugar central. Se trata del silogismo, forma de demostración sistematizada por Aristóteles y que en la sociedad colonial funcionó como el instrumento obligado de la transmisión de los conocimientos. Las diferencias y desfases entre la práctica del silogismo en la versión original de Aristóteles, su circulación en el aristotelismo medieval y el uso que de esta forma se hizo en los estudios superiores coloniales es algo que está por investigarse ${ }^{83}$. Pero el hecho que aparece por fuera de toda duda es que, tanto en el campo de la formación teológica como filosófica, sobre el marco general de los principios de Lectio, Dictatio y Disputatio, el silogismo constituyó la "tejne" dominante en que se ejercitaban a fondo los colegiales en formación y bajo la cual "leían y argüían" los catedráticos.

Vistas de cerca las cosas, la práctica filosófica colonial en las corporaciones del saber no se formó mayor problema con respecto a la Verdad pues, como se repetía entonces, "la verdad sólo Dios la sabe". El problema central del conocer no estaba centrado en la

\footnotetext{
${ }^{79}$ Véase: Quesedo, Francisco. "Manuscritos Teológico-Filosóficos Santafereños”, en: Eclesiástica Xaveriana. Número 2, 1954. pp. 291 a 294.

${ }^{80}$ Véase: Herrera, Daniel. "La filosofía en la Colonia. Elementos para una aproximación histórica", en: Ideas y Valores. Universidad Nacional. Bogotá. Nos.: 55-56. Agosto 1979. pp. 59 a 81.

${ }^{81}$ Barthes, Roland. Lección inaugural de la cátedra de semiología literaria del College de France, en: ECO, Revista de Occidente. No. 218. Diciembre de 1979. p. 184.

${ }^{82}$ Hesse, Herman. Leyendas Medievales. Barcelona, Bruguera, 1979, p. 7.

${ }^{83}$ Sobre los problemas que plantea la apropiación del aristotelismo, véase: Koyre, Alexandre. Estudios sobre la historia del pensamiento científico. México, Editorial Siglo XXI, 1977. p. 16 y ss.
} 
búsqueda de la verdad; o, dicho de otra manera, lo fundamental "para estar en la verdad" - que de todos modos se daba por sabida, era el dominio de una técnica bajo la cual debía expresarse todo razonamiento. La formación filosófica y teológica constituía un especial rito de iniciación mediante el cual se entraba "en una forma". Y el proceso de apropiación de esa forma se llevaba a cabo mediante la diaria preparación en la disputa ${ }^{84}$, lo que en el lenguaje de la sociedad colonial se denominaba "argüir", disputa cuyo resultado de antemano se sabia y en donde los contendientes podían ocupar cualquiera de las posiciones posibles en la batalla, resultando de todo ello un juego (solemne), en los términos y condiciones en que Huizinga lo definió: “... un convenio para, dentro de ciertos límites espaciales y temporales, realizar algo en una determinada forma y bajo reglas determinadas, que da por resultado la resolución de una tensión y se desarrolla fuera del curso habitual de la vida" ${ }^{85}$. Este difícil y sutil juego de entrenamiento diario en la disputa, las "diarias conclusioncillas", estaba coronado pon las fiestas magníficas en que se competía públicamente ${ }^{86}$ : los actos de conclusiones, en donde el pretendiente al trono del saber, "habiendo tomado 24 horas antes puntos por el libro de Aristóteles" (o Santo Tomás), debía demostrar su exacto conocimiento de la disputa razonando a través de complicados silogismos ${ }^{87}$.

Pero una cultura del silogismo no puede ser sino una cultura de la Lógica. En la historia de la filosofía la lógica aparece siempre cumpliendo un papel en extremo complejo. Ella "resulta necesaria cuando en el orden del pensamiento mismo se produce una crisis, cuando lo que parecía derivarse con seguridad de la reflexión existente, de las categorías y principios existentes, resulta que no se deriva" ${ }^{88}$. Pero así como ella, mediante su vinculación con el trabajo de la crítica, expresa reestructuraciones profundas en el orden del saber en momentos de acusadas crisis, también es, sin lugar a dudas, instrumento de vanalización de los conocimientos ${ }^{89}$. Esto último ha dependido siempre del estatuto que ella ha tenido hasta $\mathrm{Kant}^{90}$ y de la opinión kantiana., —que Hegel refutó, pero que en tanto opinión continúa vigente- ${ }^{91}$, de que la lógica es, después de Aristóteles, un conocimiento más o menos terminado. Aristóteles, con su formidable trabajo lógico, habría agotado todas sus formas posibles y, siendo ella el estudio de las formas puras del pensamiento con independencia del objeto tratado, actuaría como una gimnasia anterior y preparatoria al conocer ${ }^{22}$. Y en la sociedad colonial Neogranadina el entrenamiento en el uso del silogismo era el propio entrenamiento en la lógica, hipostasiando la pura forma en su aspecto más externo de ritual y cumplimiento de reglas, independientemente del contenido de la verdad.

\footnotetext{
84 “Así, la dialéctica (aristotélica) terminó por confundirse con un ejercicio, un modo de exposición, una ceremonia, un deporte, la disputatio (que podríamos llamar coloquio de oponentes)". Barthes, Roland. Investigaciones Retóricas I. (Ayudamemoria). Editorial Comunicaciones, Buenos Aires. p. 33.

${ }^{85}$ Huizinga, Johan, Horno Ludens. Madrid, Alianza Editorial. p. 98.

86 “...la disputa es una ceremonia, una justa dialéctica ejecutada bajo la presidencia de un maestro... Se trata en su conjunto de una cultura deportiva: se forman atletas de la palabra; la palabra es objeto de un prestigio y de un poder reglamentados, la agresividad está codificada". Barthes, R. Investigaciones... p. 25.

${ }^{87}$ Como lo señala Barthes, estas disputas no escapan a la interpretación analítica: "Si quisiéramos evaluar el sentido neurótico de semejante ejercicio, sin duda deberíamos remontamos a la majé de los griegos, esa especie de sensibilidad conflictual que hace intolerable para un griego (luego para un occidental) toda puesta en contradicción del sujeto consigo mismo; basta forzar un interlocutor a contradecirse para reducirlo, eliminarlo, anularlo: Calicles (en el Gorgias) deja de responder antes de contradecirse. El silogismo es el arma misma que permite esta liquidación, es el cuchillo que no se mella pero que mella: los dos antagonistas son dos verdugos que tratan de castrarse el uno al otro (de allí el episodio mítico de Abelardo, el castrador-castrado). Barthes R. Investigaciones... p. 34.

${ }^{88}$ Zuleta, Estanislao. Lógica y Crítica. p. 6.

${ }^{89}$ El papel — negativo - de vanalización de los conocimientos que a nivel de la filosofía, en ciertos períodos, cumple la lógica, es similar al que la "metodología" cumple en la actualidad en las ciencias sociales.

${ }^{90}$ Véase: Kant, Manuel. Lógica (Tratado de Lógica). México, Editora Nacional, 1972, p. 2 y ss.

${ }^{91}$ Hegel, G.W.F. Ciencia de la Lógica. Buenos Aires, Solar-Hachette, 1968. p. 48.

${ }^{92}$ Ibid. p. 52 y ss.
} 
Sin entrar en discusiones ni valoraciones sobre el silogismo como instrumento del pensar y del razonar, hay que señalar de todos modos por lo menos, algo sobre los efectos posibles que, para una sociedad, en el nivel de las "mentalidades", tiene el privilegio de la disputa silogística. Este fenómeno tiende a crear una relación muy particular con la verdad, produciendo una especie de privilegio de los aspectos más formales y vacíos y un "olvido" por la verdad y sus consecuencias, en favor del cumplimiento aplicado de pasos, reglas y procedimientos, rasgo muy acentuado en lo que se denomina una "mentalidad jurídica", deformación de la que nuestra cultura no termina por separarse. Hablando del silogismo y la retórica, Barthes dice que el mundo está increíblemente lleno de antigua retórica. Posiblemente en ninguna sociedad tengan tanta fuerza sus palabras como en la nuestra: "La disputatio ha desaparecido, pero el problema de las reglas (lúdicas, ceremoniales) del juego verbal se mantiene. ¿Cómo discutimos hoy en nuestros escritos, en nuestras reuniones, en nuestras conversaciones y hasta en las "escenas" de la vida privada? ¿Hemos terminado con el silogismo (aún disfrazado)? Sólo un análisis del discurso intelectual podrá algún día responder con precisión"93.

\section{La ausencia del Libro}

La Disputatio, a través de la técnica del silogismo, fue elemento central del régimen y método de estudios, como lo acabo de señalar. Pero estaba precedida siempre por la Lectio, la lectura de "viva vox" que el lector realizaba y que era al mismo tiempo Dictatio fijada en los cuadernos por los colegiales, cuadernos llamados "mamotretos" y en los que en gran medida quedó inscrita la huella del pensamiento teológico y filosófico colonial ${ }^{94}$.

En el universo cultural europeo, estos métodos - lectio y dictatio- de gran tradición medieval, empezaron a ser abandonados en tanto la imprenta y la producción de libros fueron ganando terreno, ocasionando modificaciones fundamentales en las formas de transmisión de los conocimientos, en la relación de los sentidos en el aprendizaje y en los hábitos de lectura ${ }^{95}$. Pero como en una especie de juego trágico de relevo, lo que fueron métodos de enseñanza abandonados en Europa en el umbral del siglo XV supervivieron 200 años en el mundo colonial Neogranadino. La imprenta fue aquí una innovación que, con algún alcance, sólo funcionó en los últimos 10 años del siglo XVIII y la circulación de libros encontró siempre trabas en el orden político y administrativo ${ }^{96-97}$. La apología corriente de las grandes bibliotecas coloniales Neogranadinas es algo que debe reducirse a sus justas proporciones y nunca podrían compararse con las de Lima o México. En el caso de los textos de filosofía se encuentran demasiadas evidencias documentales que permiten afirmar la inexistencia de cantidades suficientes de ejemplares para el uso de los colegiales. Las constituciones redactadas por Fray Cristóbal de Torres para el Colegio del Rosario mencionaban la ausencia de textos y, 120 años después, el Plan del Fiscal Moreno y Escandón vuelve a señalar la carencia de textos como un obstáculo que encuentra la implantación de los nuevos planes y métodos de estudio, queja que se repetirá aún a principios del siglo XIX.

\footnotetext{
${ }^{93}$ Barthes, T. Investigaciones... p. 35 .

${ }^{94} \mathrm{De}$ los autores de estos manuscritos y de su relación con lo que copiaban, es muy poco lo que en la actualidad sabemos. Se trataba de Scriptor (¿el que recopia pura y simplemente?) De Compilator (¿agrega a lo que copia, pero nunca algo que provenga de él mismo?) De Comentator (¿se introduce sin duda en el texto recopiado, pero sólo para hacerlo Inteligible?) De Autor (¿Da sus propias Ideas, pero siempre apoyándose en otras autoridades?) Sobre todo ello, véase: Barthes, R. Investigaciones... p. 25.

${ }^{95}$ Véase Febvre, Lucien y Martin Henri-Jean. La aparición del libro. México, Uthea, 1962: y Macluhan, Marshall. La galaxia Gutemberg. Madrid, Editorial Aguilar, 1972.

${ }^{96}$ Posada, Eduardo. Bibliografía Bogotana. 2 Vals. Bogotá, 1917. Imprenta de Arboleda y Valencia.

${ }^{97}$ Este último juicio debe matizarse en relación con los distintos períodos y los distintos géneros literarios. Así, por ejemplo, buena parte de la edición príncipe del Quijote llegó al mundo colonial.
} 
Lo que esto permite señalar es que la carencia de textos, el hecho escueto de la ausencia de libros, fue uno de los elementos que más incidió en la perpetuación de formas de enseñanza, de formas de transmisión de conocimientos que, en el contexto europeo, la invención de la imprenta había permitido superar, y tal carencia constituyó aquí una barrera largamente persistente y un argumento continuamente invocado contra la reforma de los métodos de estudios. Pero aún más, y es lo más importante, dio lugar a una Cultura del Manuscrito cuya significación y consecuencias no han sido nunca investigadas, pero de las que algo podemos sospechar. Por lo pronto señalo que facilitó, acentuó y perpetuó los criterios de autoridad en el saber (Magíster Dixit), acercando la práctica filosófica, a través de la obediencia y la repetición, dos mecanismos muy importantes en la historia de nuestras prácticas educativas, a una suerte de círculo cerrado sin posibilidad ninguna de salida. Año tras año, durante un largo período, la misma lectio, la misma dictatio, unas veces a partir de un texto impreso que el maestrolector poseía, muchas otras a partir de un cuaderno manuscrito que un estudiante había copiado sin variaciones mayores frente al texto original, si dejamos de lado los posibles lapsus y otras erratas menores. Un poco la misma historia de Pierre Menard copiando de nuevo el Quijote para crearlo otra vez.

Concluyo esta breve caracterización de la "universidad colonial", relativamente válida hasta la época de expulsión de la Compañía de Jesús, adelantándome a dos posibles objeciones.

Para empezar, se podría argumentar que los pocos rasgos anotados no resultan en manera alguna suficientes para caracterizar el complejo sistema de funcionamiento de las instituciones del saber en la sociedad colonial. A esto habría que responder recordando el punto de análisis que aquí se privilegia: la circulación de los discursos y su forma institucional de apropiación. $Y$ desde este punto de vista se trata no sólo de rasgos suficientes sino sobre todo pertinentes. De esta manera, por ejemplo, los aspectos económicos de estas instituciones y su relación con el conjunto de prácticas económicas en la Colonia, problema tan importante, se deja de lado por su escasa pertinencia dentro de los objetivos y límites de estas notas de investigación.

Se podría argumentar también, aceptando algún grado de validez a lo propuesto, que se descuidan las contratendencias presumiblemente existentes en todo fenómeno social y que se generaliza de manera muy brusca y poco matizada para un período supremamente extenso. Responderé entonces que la Formación Cultural Neogranadina fue, durante un lapso tan amplio que hoy nos asombra, de un completo monolitismo en el plano de la enseñanza denominada superior. Si bien es cierto que hubo enfrentamiento permanente entre las distintas "escuelas de partido", enfrentamiento en que se cruzaban intereses doctrinales, de prestigio y económicos, este enfrentamiento no significó durante todo el siglo XVII y buena parte del XVIII modificación alguna en las formas y enunciados en los cuales encontraba su suelo nutricio el pensamiento colonial. La dinámica de transformación de las estructuras coloniales del saber se caracterizó hasta aproximadamente 1770 por un ritmo supremamente lento, e iniciada esta transformación los propios centros del saber se mostraron, en muchos casos y situaciones, como las fuerzas más reactivas y opuestas. El proceso de formación de las generaciones que en el último tercio del siglo XVIII lanzaron una batalla de relevo cultural encontró en las universidades coloniales una respuesta abigua y contradictoria, unas veces de rechazo, otras veces de aceptación. Pero en medida no desdeñable ese proceso de cambio ideológico y cultural tuvo como centros las bibliotecas y gabinetes privados, "las tertulias y asambleas nocturnas", y toda clase de eventos un poco contrarios y marginales a las propias instituciones educativas. Pero no hay que ver en ello ninguna gran paradoja, pues tal 
marginalidad parece haber sido una constante de todo gran proceso de transformación espiritual hasta el presente. 